\title{
Uric Acid Levels Correlate with Sensory Nerve Function in Healthy Subjects
}

\author{
Alon Abraham (1), Hans D. Katzberg, Leif E. Lovblom, Bruce A. Perkins, Vera Bril
}

\begin{abstract}
Background: High levels of uric acid (UA) are associated with various peripheral neuropathies. Furthermore, uric acid levels have been found to correlate with both the clinical and electrophysiological severity of diabetic sensorimotor polyneuropathy, mainly with sensory functions. Objectives: To determine whether higher UA levels are associated negatively with nerve function in healthy subjects. Methods: A total of 126 healthy subjects recruited prospectively for another study were included. We extracted demographic data, body mass index (BMI), blood pressure, Toronto Clinical Neuropathy Score (TCNS), electrophysiological findings, vibration perception thresholds (VPT), and laboratory test results including UA, hemoglobin A1c (HbA1c), estimated glomerular filtration rate (eGFR), and lipid levels. Results: The mean age of the cohort was $56 \pm 17$ years with $56 \%$ females. Males had higher UA values compared with females. Univariate beta regression coefficient analysis between UA levels and demographic, clinical, electrophysiological, and laboratory findings showed significant positive correlations with male gender, components of the metabolic syndrome, and with VPT, while an inverse correlation was found with electrophysiological sensory parameters. A multivariate regression model showed positive correlations only with BMI, finger VPT, and triglycerides. Conclusion: Higher UA levels correlate with lower sensory nerve function in healthy subjects, expanding the evidence of possible negative influence of UA on peripheral nerves, although a causative role has not yet established.
\end{abstract}

RÉSUMÉ: Corrélations entre les taux d'acide urique et la fonction nerveuse sensorielle chez des sujets en santé. Contexte : Des taux élevés d'acide urique (AU) peuvent être associés à de nombreuses neuropathies périphériques. De plus, il a été établi que ces mêmes taux peuvent être associés au niveau de gravité, tant clinique qu'électro-physiologique, de la polyneuropathie sensorimotrice diabétique, et ce, principalement en ce qui regarde les fonctions sensorielles. Objectifs : Déterminer dans quelle mesure des taux élevés d'AU peuvent être associés négativement à la fonction nerveuse chez des sujets en santé. Méthodes : Au total, 126 sujets en santé ayant été recrutés de façon prospective dans le cadre d'une autre étude ont été inclus dans le cadre de la présente étude. Outre des données démographiques, nous avons collecté des données concernant les aspects suivants : l'indice de masse corporelle (IMC), la tension artérielle, des résultats au Toronto Clinical Neuropathy Score (TCNS), des résultats de nature électro-physiologique et les seuils de perception des vibrations. Quant à nos tests de laboratoire, ils ont fourni des résultats concernant les taux d'AU et de lipides, le pourcentage d'hémoglobine A1c (HbA1c) et le taux de filtration glomérulaire estimé. Résultats : L'âge moyen des sujets de cette cohorte était de $56 \pm 17$ ans, $56 \%$ d'entre eux étant de sexe féminin. En comparaison avec les sujets de sexe féminin, les sujets de sexe masculin ont donné à voir des taux d'AU plus élevés. Une analyse bêta uni-variée du coefficient de régression entre les taux d'AU et des données démographiques, cliniques, électro-physiologiques, ainsi que d'autres données tirées de tests de laboratoire, ont montré qu'il existe des corrélations positives notables entre le fait d'être de sexe masculin, des aspects du syndrome métabolique et les seuils de perception des vibrations. En revanche, il nous a été possible d'établir une corrélation négative avec des paramètres sensoriels électro-physiologiques. De son côté, un modèle de régression multivariée a montré qu'il existait seulement des corrélations positives entre l'IMC, les seuils de perception des vibrations des doigts et des triglycérides. Conclusion : Des taux d'AU plus élevés ont été associés à une fonction nerveuse sensorielle diminuée chez des sujets en santé, ce qui renforce l'idée, bien qu'un rôle causal n'ait pas encore été établi, d'une possible influence négative de l'AU sur les nerfs périphériques.

Keywords: Uric acid, Sensory nerve function, Polyneuropathy, VPT, TCNS, Healthy subjects doi:10.1017/cjn.2019.9

Can J Neurol Sci. 2019; 46: 337-341

\section{INTRODUCTION}

Uric acid (UA) is one of the most important circulating antioxidants. Although high UA levels might reflect an inherent response to oxidative stress, and serve as a protective mechanism to combat the generation of free radicals, UA might also function as a pro-oxidant, as the reaction of UA with oxidants may also produce other free radicals that might propagate a radical chain reaction and oxidative damage to cells. ${ }^{1}$ High UA levels are associated with various systemic disorders, including cardiovascular disease, hypertension, dyslipidemia, obesity, impaired

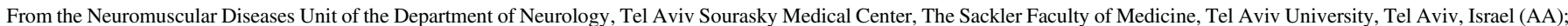

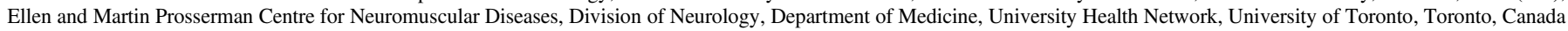

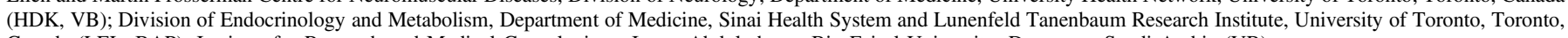
Canada (LEL, BAP); Institute for Research and Medical Consultations, Imam Abdulrahman Bin Faisal University, Dammam, Saudi Arabia (VB)

Received December 3, 2018. Final Revisions Submitted January 10, 2019. Date of Acceptance January 17, 2019.

Correspondence to: Alon Abraham, Neurologist, Tel Aviv Medical Center, 6 Weizmann St, Tel Aviv, Israel. Email: alonabmail@gmail.com 
glucose metabolism, and metabolic syndrome. ${ }^{2}$ High levels of UA are also associated with peripheral neuropathies, ${ }^{3}$ including diabetic sensorimotor polyneuropathy, ${ }^{4,5}$ and chronic inflammatory demyelinating polyneuropathy (CIDP). ${ }^{6}$ Furthermore, uric acid levels have been found to correlate with both clinical and electrophysiological severity of diabetic sensorimotor polyneuropathy, mainly with sensory functions. ${ }^{7}$ In contrast, low UA levels have been found in various other neurologic disorders, such as amyotrophic lateral sclerosis, Alzheimer's disease, Parkinson's disease, and multiple sclerosis. ${ }^{8}$ In this study, we aimed to determine whether higher UA levels are associated negatively with nerve function in healthy subjects. As high UA levels are found in various neuropathies ${ }^{3}$ and show negative correlation with nerve function in diabetic polyneuropathy, ${ }^{7}$ we hypothesized that a similar negative correlation will be found in healthy subjects, although to a lesser degree, and without clinical nerve function impairment.

\section{Materials ANd Methods}

Healthy subjects included controls recruited prospectively as part of two studies, the first aimed to identify the concurrent and predictive validity of corneal confocal microscopy to detect and predict diabetic sensorimotor polyneuropathy, and included 72 controls, ${ }^{9}$ while the second was part of the Canadian Study of Longevity in Type $1 \mathrm{DM}$, and included 75 controls. ${ }^{10}$ The Research Ethics Board of the University Health Network approved the study protocol and all patients provided informed consent.

Out of 72 controls in the first cohort, 19 were missing UA and 1 had $\mathrm{HbA} 1 \mathrm{c}>6.4 \%$, and these subjects were therefore excluded. All controls in the second cohort had UA measured; one had high $\mathrm{HbA} 1 \mathrm{c}$ and was therefore excluded.

We extracted demographic data, body mass index (BMI), blood pressure, Toronto Clinical Neuropathy Score (TCNS), electrophysiological findings, vibration perception thresholds (VPT), and laboratory test results including UA, hemoglobin A1c (HbA1c), estimated glomerular filtration rate (eGFR), and lipid levels.

The TCNS is a valid and reliable scale for diagnosing and staging of diabetic sensorimotor polyneuropathy, as well as for a wide spectrum of other polyneuropathies. The scale incorporates sensory and motor symptoms, as well as lower limb sensory and reflex findings. The score ranges from a minimum of 0 to a maximum of 19 points, and a score of 5 or below indicates no or minimal neuropathy. ${ }^{11}$ Nerve conduction studies (NCS) were performed using the Sierra Wave instrument (Cadwell Laboratories Inc., Kennewick, WA, USA) according to the standards of the Toronto General Hospital (University Health Network) electromyography laboratory. Leg temperature was measured prior to the study, and in case needed, warming was performed to ensure a surface temperature of $\geq 31.0^{\circ} \mathrm{C}$. Peroneal and sural NCS were performed using surface stimulating and recording techniques according to the standards of the Canadian Society of Clinical Neurophysiology and the American Association of Neuromuscular and Electrodiagnostic Medicine. ${ }^{12}$ Latencies, amplitudes, and conduction velocities were automatically calculated by the electromyography Instrument. Peroneal compound motor action potential (CMAP) amplitudes were measured from baseline to peak, and sural sensory nerve action potential
(SNAP) amplitudes were measured from baseline to negative peak, or from the positive peak (if present) to the negative peak. $^{13}$ VPT were determined using a Neurothesiometer (Horwell Scientific, London, UK) at the fingers and toes, and are described elsewhere. ${ }^{11}$

\section{Statistical Analysis}

Statistical analysis was performed using SAS 9.4 (SAS Institute). Data are reported as means \pm standard deviations (SD) or as frequencies. The distribution of UA was assessed for normality (Shapiro-Wilk and review of histogram). Correlations between UA and demographic, clinical, and electrophysiological parameters were explored using linear regression: for each parameter, separate univariable and multivariable regression models were constructed, with UA as the dependent variable and the parameter as an independent variable. The multivariable models included age, gender, and eGFR as covariates, which were chosen a priori due to their strong associations with AU. Regression coefficients $\beta$ are reported. Selected univariable models are presented graphically. VPT were dichotomized as normal or abnormal, with $\beta$ representing the unadjusted or adjusted difference between these groups ( $\beta>0$ implying higher UA in the abnormal group). $P$ values of $<0.05$ were considered significant; as we consider this analysis hypothesis generating, no adjustments for multiple comparisons were done.

\section{RESUlts}

The mean age of the cohort was $56 \pm 17$ years with $56 \%$ females. Electrophysiological and laboratory results and VPT were within normal limits in all subjects except six, all older than 70 years with abnormal sural and/or VPT values, which we consider normal for age. Males had higher UA values compared with females $(347 \pm 68$ vs. $277 \pm 76 \mu \mathrm{mol} / \mathrm{L}, P<0.001)$ (Table 1).

Univariate beta regression coefficient analysis between UA levels and demographic, clinical, electrophysiological and laboratory results are shown in Table 1 . We observed significant positive correlations with male gender, components of the metabolic syndrome including BMI, systolic blood pressure, and triglycerides, and VPT. An inverse correlation was found with eGFR and with electrophysiological sensory parameters, including sural nerve amplitude and conduction velocity, but not with motor parameters. A Multivariate regression model, adjusted for age, gender, and eGFR, showed positive correlations with BMI, finger VPT, and triglycerides only (Table 2 and Figure 1).

\section{Discussion}

Previous studies have shown a high frequency of elevated UA levels in various peripheral neuropathies. ${ }^{3,5-7}$ Furthermore, UA levels were found to correlate with the severity of diabetic polyneuropathy, mainly with sensory function. ${ }^{7}$ Our study results show that UA levels have an inverse correlation with sensory nerve function in healthy controls also, without clinical or electrophysiological evidence of polyneuropathy, broadening the currently known association between UA and nerve impairment to the subclinical state. Although the degree of correlation is weak, many confounders, such as genetic, metabolic and 
Table 1: Demographic, clinical, and electrophysiological findings in 126 healthy subjects

\begin{tabular}{|c|c|c|}
\hline Female gender, $n(\%)$ & $70(56)$ & \\
\hline Age (years) & $56 \pm 17$ & \\
\hline BMI $\left(\mathrm{kg} / \mathrm{m}^{2}\right)$ & $26.2 \pm 5.2$ & \\
\hline Diastolic BP (mmHg) & $77.7 \pm 9.9$ & \\
\hline Systolic BP (mmHg) & $127.6 \pm 17.2$ & \\
\hline \multicolumn{3}{|l|}{ TCNS } \\
\hline Symptoms & $0.3 \pm 0.7$ & \\
\hline Sensory deficits & $0.7 \pm 1.1$ & \\
\hline Reflexes & $1.1 \pm 1.6$ & \\
\hline Total score & $2.1 \pm 2.3$ & \\
\hline NCS & & Normal values \\
\hline Sural amplitude $(\mu \mathrm{V})$ & $13.1 \pm 7.7$ & $>6$ \\
\hline Sural CV (m/s) & $50 \pm 4.2$ & $>40$ \\
\hline Peroneal amplitude (mV) & $5.2 \pm 2.2$ & $>2$ \\
\hline Peroneal CV $(\mathrm{m} / \mathrm{s})$ & $46.9 \pm 4.1$ & $>40$ \\
\hline VPT finger (V) & $3.7 \pm 1.2$ & $<5$ \\
\hline VPT toe $(\mathrm{V})$ & $9.5 \pm 6.4$ & $<15$ \\
\hline \multicolumn{3}{|l|}{ Laboratory tests } \\
\hline eGFR (ml/min) & $86.2 \pm 14.9$ & $>60$ \\
\hline HbAlc $(\%)$ & $5.6 \pm 0.3$ & $4.5-6$ \\
\hline Triglycerides $(\mathrm{mmol} / \mathrm{L})$ & $1.3 \pm 0.9$ & $0.45-2.29$ \\
\hline \multicolumn{3}{|l|}{ Uric acid $(\mu \mathrm{mol} / \mathrm{L})$} \\
\hline Total cohort & $308 \pm 80$ & \\
\hline Males $(n=56)$ & $347 \pm 68$ & $234-529$ \\
\hline Females $(n=70)$ & $277 \pm 76^{*}$ & $172-458$ \\
\hline
\end{tabular}

$\mathrm{BMI}=$ body mass index BP $=$ blood Pressure TCNS $=$ Toronto Clinical Neuropathy Score; NCS = nerve conduction studies; $\mathrm{CV}=$ conduction velocity; $\mathrm{VPT}=$ vibration perception threshold; $\mathrm{eGFR}=$ estimated glomerular filtration rate.

* Males had significantly higher uric acid levels compared with females $(P<0.001)$. Data presented as mean \pm standard deviation, or number (percent).

environmental factors, which were not addressed in this study might influence this complex relationship. This might also explain why UA levels did not correlate with electrophysiological measures using a multivariate model, which did not account for all potential confounders, and also requires a higher number of subjects in order to reach statistical significance. However, UA might merely serve as a marker for other conditions that inversely correlate with sensory nerve function, such as obesity. ${ }^{14}$

In line with a previous study in patients with diabetic polyneuropathy, ${ }^{7} \mathrm{UA}$ showed an inverse correlation with sural nerve amplitude and conduction velocity, and a positive correlation with VPT at the fingers and toes, but not with peroneal nerve amplitude or conduction velocity. An additional similarity was the correlation with finger VPT, but not with toe VPT using a multivariate regression model. As finger VPT was measured at the pulp of the first finger, which lies within the median nerve distribution, this finding might reflect increased susceptibility to
Table 2: Univariate and multivariate beta regression coefficient analyses between uric acid levels and demographic, clinical, and electrophysiological findings in $\mathbf{1 2 6}$ healthy subjects

\begin{tabular}{|c|c|c|c|c|}
\hline & \multicolumn{2}{|c|}{ Univariate analysis } & \multicolumn{2}{|c|}{ Multivariate analysis* } \\
\hline & $\beta$ & $P$-value & $\beta$ & $P$-value \\
\hline Gender & -70.4 & $<0.0001$ & - & - \\
\hline Age & 0.2 & 0.68 & - & - \\
\hline BMI & 6.1 & $<0.0001$ & 5.3 & $<0.0001$ \\
\hline Diastolic BP & 1.1 & 0.127 & 0.6 & 0.33 \\
\hline Systolic BP & 1 & 0.02 & 0.2 & 0.56 \\
\hline \multicolumn{5}{|l|}{ TCNS } \\
\hline Symptoms & -5 & 0.64 & -0.1 & 0.99 \\
\hline $\begin{array}{l}\text { Sensory } \\
\text { deficits }\end{array}$ & 9.8 & 0.13 & -1 & 0.85 \\
\hline Reflexes & 6.6 & 0.14 & 0.87 & 0.83 \\
\hline Total score & 4.8 & 0.12 & -0.1 & 0.98 \\
\hline \multicolumn{5}{|l|}{ NCS } \\
\hline $\begin{array}{l}\text { Sural } \\
\text { amplitude }\end{array}$ & -2 & 0.03 & -0.5 & 0.63 \\
\hline Sural CV & -5.3 & 0.002 & 0.2 & 0.91 \\
\hline $\begin{array}{l}\text { Peroneal } \\
\text { amplitude }\end{array}$ & 3.5 & 0.29 & 2.2 & 0.46 \\
\hline Peroneal CV & -2.8 & 0.11 & 1.2 & 0.46 \\
\hline VPT finger & 56.8 & 0.02 & 45.3 & 0.04 \\
\hline VPT toe & 60 & 0.01 & 42.8 & 0.06 \\
\hline \multicolumn{5}{|l|}{$\begin{array}{l}\text { Laboratory } \\
\text { tests }\end{array}$} \\
\hline eGFR & -1.5 & 0.002 & - & - \\
\hline $\mathrm{HbAlc}$ & 27.3 & 0.19 & 16.2 & 0.36 \\
\hline Cholesterol & -1.3 & 0.86 & 9.3 & 0.18 \\
\hline Triglycerides & 28.5 & 0.001 & 23 & $<0.001$ \\
\hline
\end{tabular}

$\mathrm{BMI}=$ body mass index $; \mathrm{BP}=$ blood Pressure $; \mathrm{TCNS}=$ Toronto Clinical Neuropathy Score; $\mathrm{NCS}=$ nerve conduction studies; $\mathrm{CV}=$ conduction velocity; $\mathrm{VPT}=$ vibration perception threshold; $\mathrm{eGFR}=$ estimated glomerular filtration rate.

$\beta$ values represent the unadjusted (left columns) and adjusted (right columns) change in uric acid per unit change in the indicated independent variable.

*Adjusted for age, gender, and eGFR. Statistically significant $P$ values are shown in bold font.

UA levels of the median nerve at the carpel tunnel, which has been described previously in patients with polyneuropathy. ${ }^{3}$ However, as median nerve conduction studies were not included in this study, we cannot confirm this hypothesis.

Similar to the previous report, ${ }^{15}$ our study has also shown a correlation between UA levels and components of the metabolic syndrome, including BMI, systolic blood pressure, and triglycerides. Interestingly, in contrast to the association between high UA levels and polyneuropathy, low UA levels have been reported in various other neurologic diseases, such as multiple sclerosis, Parkinson's disease, Alzheimer's disease, and amyotrophic lateral sclerosis. ${ }^{8}$ A possible explanation for this discrepancy might stem 

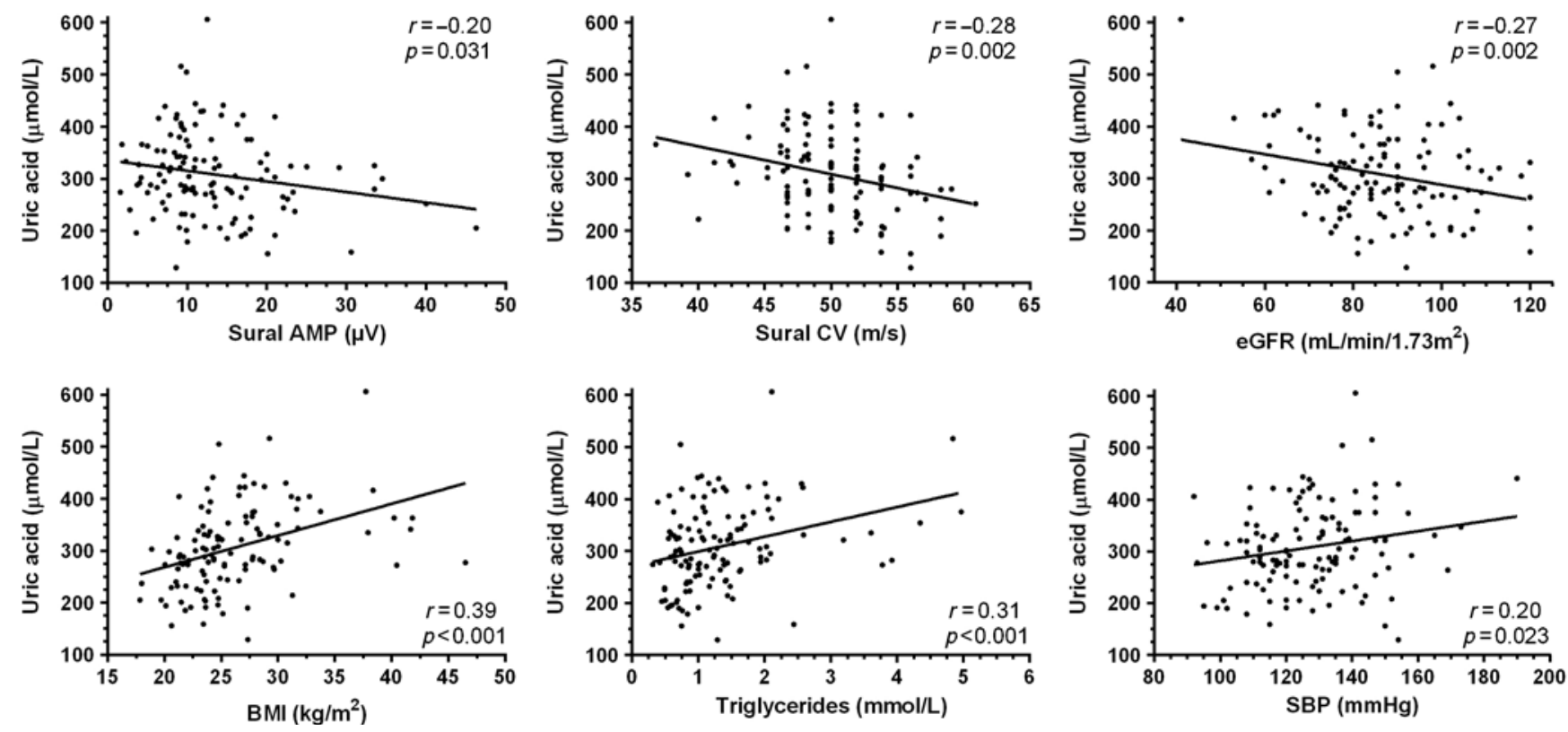

Figure 1: Relationship between uric acid and indicated variables with linear regression lines.

from different pathophysiology of polyneuropathy and mainly degenerative neurological diseases. UA is a major antioxidant in the blood, and higher levels may reflect an inherent response to oxidative stress. However, a paradoxical rise in UA levels has been observed in cardiovascular diseases. A possible explanation is that UA functions as a pro-oxidant, as the reaction of UA with other oxidants may produce free radicals leading to oxidative damage to various tissues. ${ }^{1}$ The growing evidence for the deleterious effects of UA in cardiovascular and nervous system might suggest that studies aimed at lowering UA levels, which showed positive results in systemic disorders, ${ }^{16-18}$ might need to include nerve function studies as an additional outcome measure.

This study has several limitations. The lack of significant correlations of UA levels and most sensory nerve functions in the multivariate model suggests that a higher number of subjects is required to confirm this relationship. However, it should be indicated that similar associations between UA levels and nerve function have been observed in prior studies. ${ }^{3,6,7}$ Furthermore, as this study has a cross-sectional design, and not a longitudinal evaluation, we cannot address the possible risk of accelerated nerve function deterioration in subjects with high UA levels over time. However, considering the observed modest effect of UA on nerve function, and the expected slow electrophysiological progression, a large-scale study with long-term follow-up of several years would be required to address this question.

In conclusion, the current study results show that UA levels correlate with lesser, subclinical sensory nerve function in healthy subjects, expanding evidence of possible negative impact of UA on peripheral nerves, although a causative role has not yet established. Larger epidemiological studies are required in order to confirm these findings and possible therapeutic implications.

\section{FUNDING}

Bruce A. Perkins was supported by JDRF (operating grants 17-2008-715 and 17-2013-312).

\section{Disclosures}

Hans D. Katzberg reports grants, personal fees and nonfinancial support from Grifols, personal fees and non-financial support from Genzyme, grants and personal fees from CSL Behring, grants, personal fees and non-financial support from Octapharma, personal fees from Terumo, personal fees from Akcea, personal fees from Alexion, from Pfizer, personal fees and non-financial support from Flexpharma, personal fees from Amazentis, outside the submitted work.

Bruce A. Perkins reports grants from NIH, Diabetes Canada, CIHR, personal fees from Speaker honoraria from Medtronic, Novo Nordisk, Dexcom, Abbott, Astra Zeneca, Insulet; has received research grant support from Boehringer Ingelheim and BMO (Bank of Montreal); and serves as a consultant for Insulet, Abbott, Novo Nordisk, Boehringer Ingelheim., outside the submitted work.

Vera Bril reports grants from Bionevia, grants and personal fees from CSL Behring, grants from Dainippon Sumitomo, grants from Eisai, grants and personal fees from Grifols, grants from Lilly, personal fees from Pfizer, personal fees from Alexion, personal fees from Alnylam, grants and personal fees from Shire, grants and personal fees from Argenx, outside the submitted work.

Alon Abraham and Leif E. Lovblom have nothing to disclose.

\section{Author Contributions}

Alon Abraham contributed to the study concept and design and analysis and interpretation of data; Hans D. Katzberg to the study concept and design and acquisition of data; Leif E. Lovblom to the study concept and design and analysis and interpretation of data; Bruce A. Perkins to the study concept and design and acquisition of data; Vera Bril to the study concept and design, analysis and interpretation of data, study supervision, and critical revision of manuscript for intellectual content. 


\section{REFERENCES}

1. Sautin YY, Johnson RJ. Uric acid: the oxidant-antioxidant paradox. Nucleosides Nucleotides Nucleic Acids. 2008;27:608-19.

2. Wu AH, Gladden JD, Ahmed M, Ahmed A, Filippatos G. Relation of serum uric acid to cardiovascular disease. Int $\mathrm{J}$ Cardiol. 2016;213:4-7.

3. Abraham A, Breiner A, Barnett C, et al. Laboratory abnormalities in polyneuropathy and electrophysiological correlations. Can J Neurol Sci. 2018;45(3):346-9.

4. Papanas N, Katsiki N, Papatheodorou K, et al. Peripheral neuropathy is associated with increased serum levels of uric acid in type 2 diabetes mellitus. Angiology. 2011;62:291-295.

5. Lin X, Xu L, Zhao D, Luo Z, Pan S. Correlation between serum uric acid and diabetic peripheral neuropathy in T2DM patients. J Neurol Sci. 2018;385:78-82.

6. Abraham A, Albulaihe H, Alabdali M, et al. Frequent laboratory abnormalities in CIDP patients. Muscle Nerve. 2016;53: $862-5$.

7. Abraham A, Breiner A, Barnett $\mathrm{C}$, et al. Uric acid levels correlate with the severity of diabetic sensorimotor polyneuropathy. J Neurol Sci. 2017;379:94-8.

8. Abraham A, Drory VE. Influence of serum uric acid levels on prognosis and survival in amyotrophic lateral sclerosis: a metaanalysis. J Neurol. 2014;261:1133-8.

9. Wu T, Ahmed A, Bril V, et al. Variables associated with corneal confocal microscopy parameters in healthy volunteers: implications for diabetic neuropathy screening. Diabet Med. 2012;29: e297-303.
10. Lovshin JA, Boulet G, Lytvyn Y, et al. Renin-angiotensinaldosterone system activation in long-standing type 1 diabetes. JCI Insight. 2018;3:e96968.

11. Abraham A, Barnett C, Katzberg HD, Lovblom LE, Perkins BA, Bril V. Toronto Clinical Neuropathy Score is valid for a wide spectrum of polyneuropathies. Eur J Neurol. 2018;25: 484-90.

12. Bolton CF, Benstead TJ, Grand'Maison F, Tardif GS, Weston LE. Minimum standards for electromyography in Canada: a statement of the Canadian Society of Clinical Neurophysiologists. Can J Neurol Sci. 2000;27: 288-91.

13. Abraham A, Alabdali M, Qrimli M, et al. Treatment responsiveness in CIDP patients with diabetes is associated with higher degrees of demyelination. PLoS One. 2015;10:e0139674.

14. Buschbacher RM. Body mass index effect on common nerve conduction study measurements. Muscle Nerve. 1998;21:1398-404.

15. Lee JM, Kim HC, Cho HM, Oh SM, Choi DP, Suh I. Association between serum uric acid level and metabolic syndrome. J Prev Med Public Heal. 2012;45:181-7.

16. Bomalaski JS, Clark MA. Serum uric acid-lowering therapies: where are we heading in management of hyperuricemia and the potential role of uricase. Curr Rheumatol Rep. 2004;6:240-7.

17. Volterrani M, Iellamo F, Sposato B, Romeo F. Uric acid lowering therapy in cardiovascular diseases. Int J Cardiol. 2016;213: 20-2.

18. Takir M, Kostek O, Ozkok A, et al. Lowering uric acid with allopurinol improves insulin resistance and systemic inflammation in asymptomatic hyperuricemia. J Investig Med. 2015;63:924-9. 